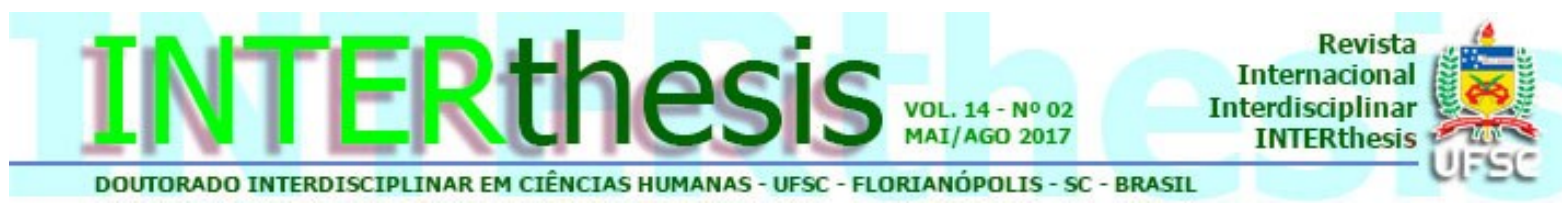

\title{
CULTURA DA VIOLÊNCIA, DISPOSITIVO DO AMOR-PAIXÃO, SEXUALIDADE E MACHISMO: UMA ANÁLISE DO DISCURSO FEMININO EM RELACIONAMENTOS CONTURBADOS
}

Ângela Maria Rubel Fanini ${ }^{1}$ Marcia Lopes dos Santos ${ }^{2}$ Gilberto Gnoato ${ }^{3}$

\section{Resumo:}

Este artigo analisa as postagens virtuais de mulheres visitantes de Blog, focado em problemas conjugais. A violência dos casais é analisada pela perspectiva relacional de Santos e Izumino (2005). Sobre o machismo, adotamos a premissa de Castañeda (2006), que o destaca como um discurso e prática não exclusivos dos homens. A ideologia do amor-paixão (Rougemont, 1988) também fortalece a cultura de violência. Partimos também das contribuições de Foucault (1982, 1984, 2012, 2013) sobre o poder e a violência, enquanto relacional, e o dispositivo da sexualidade como outro fator que leva à violência. A pesquisa espera contribuir para uma reflexão sobre a violência contra a mulher e os relacionamentos conjugais, enfatizando a necessidade de alterar os paradigmas culturais, que reforçam atitudes e discursos violentos dentro e fora da família.

Palavras-chave: Cultura da violência. Discursos sobre o Feminino. Sexualidade. Amor-paixão. Machismo.

\section{DELIMITAÇÃO DO CORPUS: O SOFRIMENTO AMOROSO NAS FALAS FEMININAS NO UNIVERSO SÓCIO-VIRTUAL}

O objeto de análise deste artigo são falas femininas, cujo conteúdo principal consiste em reclamações advindas de sofrimento causado por relacionamentos conjugais deteriorados. Essas falas advêm de sítio eletrônico que esteve em funcionamento no período entre 2011- 2014, contando com o registro de 1882 (um mil oitocentos e oitenta e duas) perguntas e comentários de visitantes mulheres, na busca de respostas para seu infortúnio amoroso. Percebeu-se que o público feminino ali apresentava-se ávido por obter soluções para a sua conduta e a de seus

\footnotetext{
1 Doutora em Teoria da Literatura pela Universidade Federal de Santa Catarina. Pós-doutorado na Universidade de Aveiro, Portugal. Professora dos cursos de Letras e Comunicação Institucional da Universidade Tecnológica Federal do Paraná e no Programa de Pós-Graduação Interdisciplinar em Tecnologia e Sociedade da Universidade Tecnológica Federal do Paraná, Curitiba, PR, Brasil. Bolsista de Produtividade em Pesquisa do CNPq. E-mail: rubel@utfpr.edu.br

2 Doutoranda do Programa de Pós-Graduação Interdisciplinar em Tecnologia e Sociedade da Universidade Tecnológica Federal do Paraná, Curitiba, PR, Brasil. E-mail: marcialopes 1@hotmail.com

3 Doutorando do Programa de Pós-Graduação Interdisciplinar em Tecnologia e Sociedade da Universidade Tecnológica Federal do Paraná, Curitiba, PR. Pesquisador do CNPq. Psicoterapeuta e Professor da Universidade Tuiuti, Curitiba, PR, Brasil. E-mail: ggnoato@onda.com.br
} 
parceiros. Essas mulheres encontraram uma porta que se abriu tal como um acesso ao atendimento psicológico e puderam compartilhar suas desditas conjugais, familiares, existenciais. Focou-se nas análises discursivas da linguagem, apostando que a investigação e a análise dos discursos são fontes importantes para entender a ação das pessoas na sociedade. A linguagem informa a forma como pensamos e quais são os nossos valores sobre o feminino, o masculino, a família, a política, a educação, ou seja, sobre a sociedade em que vivemos, trabalhamos e amamos. A linguagem violenta também contribui para uma ação violenta, demonstrando que estamos imersos em uma cultura da agressão de longa duração, que atinge a todos, constituindo seres humanos que se relacionam por intermédio de dominação, submissão e agressão.

Das 1882 perguntas e comentários, delimitamos 894 registros, cujo teor majoritário constituía-se de queixas, que se repetiam mais substantivamente acerca do sofrimento amoroso, excluindo 419 perguntas menos representativas. A partir desse passo, selecionamos alguns agrupamentos de queixas, às quais denominamos de categoria. Categoria 1 - Agressão e Submissão: ocorrem reclamações sobre violência psicológica (humilhação, depreciação, xingamento) e agressão física. Categoria 2 - Esperança e Culpa: informa-se o esforço para manter ou recuperar a relação com seus parceiros, culpando-se da própria conduta amorosa. Categoria 3 - Ciúme e Controle: reclama-se do ciúme, da posse, do domínio e do controle de seus parceiros. Categoria 4 - Infidelidade conjugal: destaca-se a infidelidade masculina. Categoria 5 - Sexualidade: ocorre a queixa, envolvendo problemas com a sexualidade, a beleza física e o uso de sítios pornográficos.

Tomamos o devido cuidado para não identificar as respondentes. As postagens estiveram no espaço virtual de modo público, o que nos permitiu selecioná-las. Com o fito de delinear um perfil de nossas postagens, elaboramos um questionário on-line, solicitando que as reclamantes o respondessem. Este permaneceu no ar por duas semanas. A devolutiva nos fez chegar ao seguinte perfil.

Quanto à localização geográfica, $82 \%$ das participantes residem no Paraná. Visitantes de outros Estados se distribuíram pela ordem entre o Rio Grande do Sul, Santa Catarina, São Paulo, Minas Gerais, Espírito Santo, Goiás, Distrito Federal e Alagoas. Assim, a amostragem é nacional, indicando uma generalização dos 
problemas. Em grau de instrução: $51 \%$ possuem nível superior completo, duas mestras e uma doutora, e $21 \%$ cursam o nível superior. Apenas 3\% por cento têm o ensino fundamental incompleto e $10 \%$ terminaram o ensino médio. Trata-se de uma amostra predominantemente de mulheres instruídas. Isso aponta que mulheres instruídas formalmente permanecem em situação de risco. Quanto ao trabalho, a maior concentração de profissões é derivada da formação nas ciências humanas (advogadas, psicanalistas, psicólogas, jornalistas, projetistas, gerente de design, servidoras públicas e bancárias). Esse dado indica a não dependência material das mulheres que, mesmo assim, permanecem em relacionamentos conturbados. Sobre a idade, a maior concentração etária incidiu sobre a faixa dos 31 aos 40 anos (34\%). A segunda maior faixa de idade foi a de 21 a 30 anos (31\%). Em terceiro lugar, dos 41 aos 50 anos (28\%). Nossa análise encontra forte base na questão da sexualidade e da paixão, dispositivos que atingem faixas etárias mais jovens. Quanto ao estado civil, $40 \%$ são casadas e $34 \%$, solteiras. O restante distribuído entre divorciadas, separadas e outros estados civis. Ao serem indagadas sobre quantas vezes foram casadas, $59 \%$ experimentaram apenas um casamento, $16 \%$ foram casadas duas vezes e $3 \%$ passaram pela experiência de três casamentos. Isso demonstra estabilidade nas relações.

\section{BREVE CONTEXTO BRASILEIRO DA VIOLÊNCIA}

Nesta seção, apresentamos um breve contexto sobre a violência no Brasil. Não intentamos apresentar a totalidade desse contexto, mas levar o leitor a perceber nossa inserção em um cenário altamente violento, que corrobora para impactar a microesfera dos relacionamentos conjugais. Um contexto social de agressão generalizado, por séculos reforçado, influencia o universo das famílias e dos relacionamentos interpessoais. A esfera macrossocial interfere na microssocial e vice-versa.

O Brasil foi a última nação a abolir a escravatura de negros no século XIX e ainda vivemos fortemente a tradição da herança escravista e escravocrata, patriarcal e as memórias do coronelismo e das ditaduras civil e militar, pelas quais passamos. A constituição da nação, desde o achamento até nossos dias, dá-se em um contexto de muita violência - genocídio dos indígenas pelos portugueses; escravidão africana de quatro séculos; coronelismo no campo; universo do favor e do clientelismo; 
política enquanto lugar majoritário dos homens; proibição às mulheres de votarem até 1930; ditaduras civis e militares até 1980; violência na questão fundiária. Esse cenário histórico forma os cidadãos e estes o reforçam em suas ações cotidianas. Causaria estranheza se o ambiente íntimo, da família, da pessoa, não fosse parte desse cenário. Obviamente que há movimentos de resistência e é nessas lutas que a violência também se institui. Nada fica imune a esse contexto, embora alguns lutem contra ele. Mas a luta também se investe de agressão. Nossa ideia é que a violência entre casais é também fruto dessa constituição da nação, visto que são os indivíduos que formam a sociedade.

O país conta hoje com a quarta maior população carcerária do planeta, atrás apenas da Rússia, da China e dos Estados Unidos. São quase 570.000 mil presos, além de 148 mil outros em regime domiciliar, em um sistema prisional com capacidade para aproximadamente 358.000 presos, formando um déficit de aproximadamente 210 mil vagas ${ }^{4}$.

Dados atuais do $10^{\circ}$ Fórum Brasileiro de Segurança Pública, realizado em novembro de 2016 , dão conta de que $57 \%$ dos brasileiros apoiam a afirmativa "bandido bom é bandido morto". No ano de 2015, esse índice era de $50 \%$. Os dados apontam para o crescimento da violência no Brasil que, em números absolutos, é o país que mais mata. Assim como possui a polícia que mais mata pessoas no mundo. Entre a população carcerária, a lei de Talião, "olho por olho dente por dente" é uma prática instituída. Quando um estuprador, um pedófilo ou um assassino de mulheres entra no presídio, já está fadado a um destino trágico entre os colegas de cela. Antes de morrer ele será tratado como "mulherzinha", na linguagem carcerária, pois passará a prestar serviços domésticos de limpeza até serviços sexuais.

A particularidade que nos interessa é o fato de que se os homens matam e morrem mais; por outro lado, o índice de mulheres que assassinam homens é incomparavelmente menor ao índice de mulheres assassinadas por homens. Em 2013, foram mortas no Brasil 4.762 mulheres, e em 2014 foram computados 4.918 assassinatos de mulheres. Eis uma passagem importante do Relatório Global Study on Homicide $2013^{5}$ :

\footnotetext{
4 Dados do Conselho Nacional de Justiça (CNJ).

${ }^{5}$ O Global Study on Homicide 2013 foi preparado pelo Escritório das Nações Unidas sobre Drogas e Crimes (UNODC).
} 
O homicídio praticado pela família ou por parceiros da vítima afeta desproporcionalmente as mulheres: dois terços das vítimas de homicídio globalmente são mulheres (43,6 mil em 2012) e um terço (20 mil) são homens. Quase metade (47\%) de todas as mulheres vítimas de homicídio em 2012 foi morta por parceiros ou membros da família, comparado a menos de $6 \%$ das vítimas de homicídio do sexo masculino. Portanto, enquanto um grande número de mulheres vítimas de homicídio é assassinado por pessoas que se espera cuidar delas, a maioria dos homens é assassinada por desconhecidos (UNITED NATIONS OFFICE ON DRUGS AND CRIME, 2013, p. 23).

Nos últimos dez anos, o homicídio de mulheres no Brasil cresceu $21 \%$. O Mapa da violência 2015 informa que em 2013, a cada dia em nosso país, 13 mulheres eram assassinadas. O Brasil ocupa hoje o quinto lugar entre as nações que mais matam mulheres no mundo. Quase a totalidade das mortes é causada por parceiros ou ex parceiros, utilizando arma de fogo (48,8\%). Referimo-nos à violência letal, mas os dados do Mapa 2015 dão um panorama pouco divulgado, em função da sua imaterialidade: a violência não letal divide-se em violência física e violência psicológica. Essas atingem todas as etapas de desenvolvimento da mulher, desde a infância até a velhice, e aumenta à medida que as meninas se tornam jovens. É progressiva para as mulheres também na vida adulta e na velhice, enquanto para os homens ela diminui à medida que os meninos se tornam jovens e adultos. Por isso, a incidência de atendimentos registrados pelo Sistema Único de Saúde (SUS), em 2014, é constante e maior entre as mulheres.

Em todas as etapas da vida, preponderam os atendimentos femininos. A incidência vai crescendo a partir de um certo equilíbrio entre os atendimentos a crianças, quando $54,1 \%$ são meninas e aumenta até a idade adulta, quando $71,3 \%$ dos atendimentos são de mulheres e só $28,6 \%$ são de homens (WAISELFISZ, 2015, p. 42).

Mesmo com a Lei Maria da Penha sancionada em 2006, os dados do SUS em 2014 mostram que metade $(49,2 \%)$ dos agressores volta a agredir suas parceiras. A reincidência aumenta um pouco mais no caso das mulheres adultas: de 30 a 59 anos. Convém destacar que, se o número de assassinatos é menor na fase adulta do que entre 18 e 30 anos, o número relativo à violência física é maior entre 30 e 59 anos. Esse breve caminhar pelos dados de nossa história secular e cotidiana pode contribuir para localizar a violência doméstica como caudatária de um contexto de longa e curta duração, que engloba o ambiente familiar. 


\section{VIOLÊNCIA SISTÊMICA E CULTURAL: DISPOSITIVOS REPRODUZIDOS EM VÁRIAS INSTÂNCIAS COMO CATEGORIAS QUE ENFORMAM OS DISCURSOS E LEVAM À AGRESSÃO}

Como pudemos perceber, a figura masculina protagoniza o quantitativo da agressão no Brasil. Vários são os dispositivos culturais que contribuem para instituir uma identidade violenta ao homem: o elogio do guerreiro, do conquistador, do lutador de artes marciais, de boxe; daquele expert no uso de armas; do colonizador etc, todos bem imortalizados pela literatura, pela imagética, pelos filmes, pelo imaginário cultural e social. Há milhares de películas que condecoram os heróis de guerra, super-heróis; propagandas de produtos que reforçam a identidade masculina, como desodorantes, carros velozes, bebidas alcoólicas, tendo como personagens homens fortes e viris; milhares de esculturas e pinturas, que destacam a figura do guerreiro; a literatura epopeica, que vangloria os feitos heroicos de dominadores de impérios; jogos (realidade virtual), que fazem apologia da morte, da vingança, tendo como personagens principais, sobretudo, os homens. Cria-se o ideal de masculinidade associado à virilidade. Mas o que faz com que esse dispositivo também se reforce são as falas do cotidiano, a que chamamos ideologia do cotidiano ${ }^{6}$ (BAKHTIN/ VOLOCHÍNOV, 2014) e a que todos nós, em menor ou maior grau de conscientização, aderimos, pois estamos dados nessa teia discursiva. O discurso não é apenas um código técnico do qual nos valemos com total consciência do que dizemos, falamos, proferimos, escrevemos. O que dizemos nos constitui como sujeitos, muitas vezes assujeitados, mediante formações discursivas de longa e curta duração. Para a Análise do Discurso baseada em Michel Foucault (2012), nós somos falados pelo discurso, ou seja, ele nos fornece uma identidade. O sujeito é dado nas malhas discursivas de uma dada cultura e contexto histórico. O discurso é também um cárcere que aprisiona o sujeito em preconceitos, conceitos e julgamentos, que podem levar a uma existência precária e degradante. A obra do filósofo ajuda-nos a pensar sobre essas formações discursivo-culturais e, nessa reflexão, pode-se vislumbrar uma saída para uma existência menos assujeitada. $O$ machismo, o patriarcalismo, o elogio do agressor masculino nos vêm pelas palavras

6 Os filósofos russos apostam na "ideologia do cotidiano", que consiste na massa discursiva de todo dia, em que se debatem, problematizam, reforçam-se valores, conceitos e preconceitos. Em nossa pesquisa, as postagens, nas quais as questões de relacionamentos conjugais são debatidas, são exemplos típicos da ideologia do cotidiano. 
e por toda uma configuração cultural que está dada em nossa linguagem. Nossa consciência e atos são diretamente instituídos por esses formadores. Nossas falas cotidianas destacam muitos dos preconceitos e conceitos que vão fornecendo uma identidade masculina em que a violência prepondera. Nesse sentido, a Análise do Discurso auxilia para interpretar as falas de nossas reclamantes, vendo essas manifestações discursivas dentro de um macrocontexto. Os exemplos se avolumam e demonstram o quão deletérias são essas falas que reproduzimos sem pensar no alcance das mesmas. Eis alguns exemplos: "A mãe diz ao filho: Espere só seu pai chegar.", "Você vai levar desaforo para casa?", "Deixe só seu pai saber disso.", "Você vai reagir, ou sou eu o homem da casa?", "Vou chamar meu marido?", "Filho, você é um homem ou uma mulherzinha?", "Você é um homem ou é um frouxo?", "Esse é macho mesmo; não se acovarda". Os exemplos se multiplicam e esse aparato discursivo-cultural, que manifesta os homens como seres violentos, constrói uma identidade agressora que a todos contamina em maior ou menor grau. Há um imaginário visual e discursivo que tem, por milhares de anos, fomentado o homem guerreiro, invasor, dominador, portador de armas. Esses discursos de longa duração moldam ações violentas, que se estendem até a contemporaneidade.

Neste artigo, distanciamo-nos das leituras exclusivamente materialistas que enfatizam a questão de classe econômica das mulheres agredidas (há pesquisas que apenas destacam a pobreza material das mulheres como fator de submissão) e das abordagens que concentram a violência em um segmento desarticulado de sentido social, como se ela fosse produto de uma ação unívoca do indivíduo. O trabalho das sociólogas Santos ${ }^{7}$ e Izumino ${ }^{8}$ (2005) dá uma revisão dos últimos 25 anos de pesquisa sobre a violência contra a mulher e serviu como marco para a escolha da "corrente relacional", que se afasta de perspectivas polarizadas, que definem o homem como algoz e a mulher como vítima. Acolhemos essa interpretação, ampliando o lado relacional ao dialógico ${ }^{10}$. O que nos interessa não

\footnotetext{
${ }^{7}$ Cecília Macdowell Santos é socióloga, pesquisadora do Centro de Estudos da Universidade de Coimbra e professora do Departamento de Sociologia da Universidade de São Francisco, Califórnia.

${ }^{8}$ Wânia Pasinato Izumino é socióloga e estuda a violência contra a mulher. Pesquisadora do Núcleo de Estudos da Violência (N.E.V) da USP.

${ }^{9}$ A corrente relacional, a partir dos anos 90 , passou para o cenário dos estudos feministas no Brasil.

10 Percebemos que a noção relacional pode ser lida como dialógica. Emprestamos esse termo a Bakhtin, em cuja obra, destaca o dialogismo como categoria fundante do sujeito, da cultura, da economia, da política. Neste artigo, percebemos a violência contra a mulher de modo dialógico. Não é fruto apenas de um único elemento (quer seja o poder masculino ou a carência econômica ou outro).
} 
são eles (agressores) ou elas (vítimas). Não analisamos o que os separam, mas as tramas culturais e discursivas que amarram partes nas relações de violência.

Inclinamo-nos a despolarizar a dicotomia - eles agressores e elas vítimas -, sem com isso recair em outra polarização- a de que se culpem as mulheres de permanecerem convivendo em situação de risco, como se a elas pesasse o ônus sobre um desejo de sofrer. Percebemos que a mulher não é nem culpada e nem produtora voluntária da violência "mas faz continuamente se amarrar às relações de violência" (MACHADO, 1998, p. 28), permanecendo, consentido e sustentando uma relação problemática.

Admitimos que, se é o homem o agressor, é para ele também muito difícil ficar do lado de fora e não aderir ao ideal de masculinidade que a cultura da virilidade e da força física lhe impõe; é igualmente difícil para a mulher não aderir ao ideal de feminino centralizado na beleza, na sedução e na paixão romântica. Esse é o jogo que se impõe a todos e ao qual nós aderimos, com resistência baixa, média ou alta. Também é necessário perceber o quanto o elemento feminino reforça o valor do homem viril, forte, líder, autoritário; e de como reproduz um discurso que a empodera, se estiver na convivência, na proteção e na relação de dependência com esse ideal de homem. É uma armadilha discursivo-cultural, na qual quase todos e todas caímos. O preço é a violência, a assimetria, a hierarquização e a polarização em que um está no pedestal e outro está a entronizá-lo. Talvez essa constatação de que a violência é relacional e dialógica, ou seja, ambos aderem a ela, possa ser uma saída para se construir uma sociedade mais fraterna entre os casais. Nossa interpretação, então, se vale de uma abordagem relacional e dialógica da violência e essa perspectiva vai ao encontro da visão de poder de Michel Foucault. O pensador não entende o poder como algo centralizado, exercido só por um polo da relação, mas como uma microfísica, que é exercida por todos. No caso das relações conjugais, embora violentas sobre a mulher (os dados de mortandade não mentem), também se instituem de forma dialógica, já que o elemento feminino contribui para reforçar o cenário violento, à medida que reproduz em suas práticas cotidianas, com suas filhas, amigas, com seu corpo, suas falas, um conjunto de valores, que favorecem a construção de uma identidade masculina perversa. Há aí uma e estas são por aquelas reforçadas, enfatizando-se a dialogia e não a dicotomia. A não polarização também encontra amparo na noção foucaultiana (1982) de poder que é, essencialmente, relacional.

R. Inter. Interdisc. INTERthesis, Florianópolis, v.14, n.2, p.132-151 Mai.-Ago. 2017 
microfísica da violência ${ }^{11}$ que encarcera a todos e todas, nas falas, nas depreciações morais, nas cobranças de conduta, que fortalecem um ambiente doméstico violento.

Obviamente que esse fato cultural de longo e substantivo alcance não inocenta os assassinos de mulheres, que devem ser julgados e condenados pela lei, mas, se não agirmos nos valores, teremos, com certeza, cada vez mais homens enjaulados e mulheres assassinadas. A partir das falas captadas, pudemos perceber que três grandes discursos-culturais de longa duração são constantemente acionados para nortearem as condutas das relações interpessoais.

\title{
5 DISPOSITIVOS DO AMOR-PAIXÃO, DA SEXUALIDADE E DO MACHISMO: RECORRÊNCIAS NAS FALAS DAS MULHERES
}

Partindo das falas das mulheres nas postagens, detectamos certas recorrências que sinalizam para os dispositivos do amor-paixão, da sexualidade e do machismo. A esses três arcabouços, chamamos de "dispositivo", tal como o concebe Foucault. No decorrer de sua vasta obra, Foucault enfatiza essa terminologia, que abarca mais que o discurso.

\begin{abstract}
Através deste termo tento demarcar, em primeiro lugar, um conjunto decididamente heterogêneo que engloba discursos, instituições, organizações arquitetônicas, decisões regulamentares, leis, medidas administrativas, enunciados científicos, proposições filosóficas morais, filantrópicas. Em suma, o dito e o não dito são os elementos do dispositivo. O dispositivo é a rede que se pode estabelecer entre estes elementos (FOUCAULT, 1982, p. 244).
\end{abstract}

Para o pensador francês, o discurso não é dado na perspectiva sistêmica estruturalista, visto que é uma realidade amparada em outras dimensões extradiscursivas. Não toma sua força e significado a partir de um sistema fechado de signos, que se remetem entre si, mediante uma lógica interna ao sistema de oposições e semelhanças. O discurso é dado dentro do contexto cultural, social, legal, sendo balizado, acreditado, incentivado, ritualizado ou interditado conforme os regimes sociais de verdade em que se insere e circula. Desse modo, Foucault

\footnotetext{
11 Tomamos o termo emprestado de Fanini (1991), sobre as relações de amor e violência na literatura. A pesquisa parte de Foucault, destacando a microfísica do poder, que se exerce de todos contra todos e não só de um poder central sobre os subordinados. Aplica-se aos relacionamentos violentos não espetaculares, que são recriados esteticamente em obras da literatura. São aí descritos como microfísicos, ocorrendo no nível discursivo, psicológico, em oposição aos traumas físicos. Nesse sentido, utilizaremos em nosso estudo, percebendo que nas microações e falas cotidianas reforçamos uma cultura da agressão, independente de nosso gênero.
} 
entende o discurso como um componente do dispositivo em virtude de que o contexto social, histórico, político, científico engloba-o, auferindo-lhe credibilidade ou desqualificando-o. A posição é de uma perspectiva translinguística para o discurso. Assim, nossas falas, em tela, serão examinadas sempre remetendo ao contexto social mais amplo de onde elas advêm.

O dispositivo do amor-paixão é recorrente nas falas. Rougemont (1988) trata dessa questão, destacando que esse "amor" vem sendo construído e reforçado ao longo dos séculos no Ocidente. O filósofo analisa as dimensões históricas e culturais dessa tipologia do amor, encontrando, mais precisamente, a genealogia do que ele chama de amor-paixão, situada na corte alemã do século XII. O autor situa nesse tempo e lugar as relações impossíveis e idealizadas do amor entre o cavaleiro medieval e a dama da corte. É com a tragédia de Tristão e Isolda que inicia a análise sobre esse sentimento e prática difundidos. Passa a analisar inúmeras obras artísticas veneradas pelo Ocidente em que esse amor se consolida, sai das fronteiras da da arte e passa a fazer parte do cotidiano da sociedade, erigindo-se em um ideal amoroso a ser alcançado. Centenas de documentos vão sendo arregimentados para comprovar que, no Ocidente, o que prevaleceu foi essa prática amorosa, que conquistou as atitudes e colonizou os comportamentos, levando, não raras vezes, a ruína aos casais. O pensador tem uma posição contrária a essa forma de amar, pois a percebe como algo que, ao exigir dos amantes uma unidade, um fechamento entre si, uma paixão avassaladora, um isolamento do casal frente ao social, leva os amantes a um ideal de relacionamento bastante perturbado, porque muito enclausurado. Em contrapartida, enfatiza o amor ágape, que não objetiva o domínio, o controle, o insulamento, pois é dado em uma chave de maior liberdade, solidariedade, respeito às diferenças. Para Rougemont, teríamos outra configuração ocidental, se tivéssemos optado por reforçar o amor ágape ao invés do amor-paixão. Este age como se os amantes tivessem tomado um "filtro amoroso", que os incapacitasse para o pensamento racional. Nessa pesquisa tomamos o amor-paixão como um dispositivo discursivo-cultural de longa duração, que ainda atinge os amantes modernos, uma vez que, no nosso corpus, ele se acha presente como uma das formas de sofrimento e desenlace trágico. $\mathrm{O}$ pensador assevera sobre a difícil articulação entre amor- paixão e casamento: 
Desde sua gênese, no século XII, o amor-paixão se revelou hostil ao casamento; as finalidades de Eros e de Ágape estão em relação de antinomia sistemática; eis o que tentei estabelecer. Procurei sublinhar os contrastes, indicar os incompatíveis, como preâmbulos das opções que todo homem deve fazer e que julga, com ou sem razão, fazer livremente. Tentei isolar a paixão como se faz com um corpo químico para melhor conhecer suas propriedades. E mostrei que, isolada de seu contrário (o amor ativo ou ágape), no estado puro, passivo ou estático, ela é mortal, como no caso de Tristão e alguns dos grandes místicos. Resta saber o que ela pode produzir quando entra em composição - se é que o tolera. O cloro puro é mortal, mas o cloreto de sódio é o sal de nossas refeições - de nossos ágapes (ROUGEMONT, 1988, p. 269).

Para este artigo, em decorrência do espaço, exemplificamos com duas postagens de nosso corpus em que detectamos esse dispositivo.

[...] porque uma paixão mexe tanto assim com as pessoas? É tão errado assim largar tudo pra viver uma paixão? Eu como sou sonhadora fico triste ao pensar que é tão grave assim viver uma paixão e pensar que paixão pode ser tão ruim assim [...] (REGISTRO 424).

Oi DR boa tarde, tenho um casamento conturbado, mas nem sempre foi assim, os problemas da vida nos levaram a isso, sei que sou em parte culpada mas sempre procuro ver meus erros e não os repetir pois eu o amo $d+[\ldots]$ ele quer viver sozinho [...] e agora se peço um beijo ele nega, na cama demora d mais pra acontecer pelo menos $15 \mathrm{em} 15$ dia não acho que isso seja normal eu o quero muito não serei capaz de seguir sem ele tenho uma dependência sentimental muito grande dele fiz de td por ele me dei ao máximo me anulei me ajude estou desesperada (REGISTRO 206).

Vemos, no primeiro excerto, que a palavra "paixão", em quatro linhas, ocorre quatro vezes, evidenciando um poder muito grande dentro do relacionamento. A paixão e sofrimento são quase sinônimos, nesse contexto. Não há razão para tanto sofrimento, mas a reclamante permanece emaranhada. Há, no entanto, uma dúvida sobre essa vida miserável e tenta compartilhar isso no sítio. Mostra claramente que está tomada por esse filtro amoroso, despossuída quase totalmente de sua racionalidade, que a poderia libertar de tal sofrimento. A felicidade, a satisfação, a harmonia, o sucesso parece que só podem acontecer dentro de um contexto amoroso em que um é o outro. A paixão é uma desrazão que controla o sujeito, anulando-o para as demais atividades, que não se centram no objeto amado. Percebe-se também que a reclamante generaliza o seu sofrimento ao usar a expressão "pessoas", parecendo acreditar nessa superestrutura amorosa que a todos avassala. Essa estrutura transcende o sujeito, dominando-o e neutralizando-o.

No segundo fragmento, ocorre também a quase total dependência do outro. Os vocábulos, "conturbada", "culpada", dependência, "anulei" "d+", atestam o 
desespero, a subserviência, a desrazão que domina o elemento feminino, ao se perceber enjeitada. A esperança do "verdadeiro amor" ou do "amor da minha vida" torna-se um destino para a vida de quem é hipnotizada pelo dispositivo do amorpaixão-romântico. A criação desse ideal amoroso que nos vem de longa data, como mencionado, é forte componente de insatisfação. Destaca-se a incapacidade da vida de seguir um curso normal, uma vez que esse amor-paixão romântico é avassalador ou já não existe mais na intensidade de antes. Essa forma de prática amorosa, com certeza, é muito violenta em relação ao sujeito que a ela se avassala, pois lhe priva de seguir adiante, como é afirmado na postagem: "eu o quero muito não serei capaz de seguir sem ele". Perceba-se como a mulher se desqualifica e se desvaloriza perante o homem. Assume uma existência totalmente fundada nesse elemento masculino e, na ausência dele, passa à inexistência. Ocorre a anulação do sujeito, em uma relação alienada, que tudo aposta (seu corpo, mente, desejos, sonhos, ambições) no outro. A não identidade da mulher advém da identidade supervalorizada do outro em uma dialogia ${ }^{12}$ perversa.

O dispositivo da sexualidade também ocorre nas queixas femininas. Aqui nos valemos de Foucault que tratou da sexualidade como um discurso e dispositivo que também pode encarcerar os sujeitos. Para ele, até o final do século XVIII, o sexo era vivido e praticado apenas como um "impulso sem nome", (1984, p. 146). Mas, a partir daí, há todo um empenho social, que objetiva descrever, dissertar, narrar, conceituar a sexualidade. Nela se encontra a verdade de homens e mulheres. A sexualidade, criada nos discursos e dispositivos, é antes produtora que repressora. À medida que passa a ser objeto discursivo intenso, manifesta-se cada vez mais desejada:

Poder falar da sexualidade se podia muito bem e muito, mas somente para proibi-la. Mas eu quis enfatizar duas coisas importantes. Primeiro, que o esclarecimento, a "iluminação" da sexualidade não foi feita só nos discursos, mas também na realidade das instituições e das práticas. Segundo, que as proibições existem, são numerosas e fortes. Mas que fazem parte de uma economia complexa em que existem ao lado das incitações, de manifestações, de valorizações. São sempre interditos que são enfatizados (FOUCAULT, 2013, p. 230).

Com o "dispositivo de sexualidade", a sexualidade se torna um fundador de sentido e de finalidades, porque passa a dizer o que o sujeito é. A sexualidade

12 O termo dialogia, tomado de Bakhtin, não pode ser entendido só em sua positividade, ou seja, gerando consenso, mas também como eterno embate relacional, que pode gerar dissenso, infortúnios e incomunicabilidade.

R. Inter. Interdisc. INTERthesis, Florianópolis, v.14, n.2, p.132-151 Mai.-Ago. 2017 
passa a ser uma categoria ontológica em meados do século XIX. E essa alteração se acirra, sendo o sexo tomado como identidade para o sujeito, uma centralidade para homens e mulheres, que são incentivados a exercerem sua sexualidade e a narrarem suas práticas, instituindo-se como sujeitos nesse narrar constante. Para Foucault, o dispositivo da sexualidade surgiu de tal forma que acreditamos nos reconhecer nele (FOUCAULT, 1984, p. 146). Seu poder tornou-o um "significante único". O sexo deve existir ao alcance de todos como um exercício cotidiano. A sexualidade tornou-se uma das dimensões centrais da vida humana. Reverbera em todos os lugares, não apenas na genitalização, mas na sua erotização discursiva, imagética, cinematográfica, musical, novelesca, e materializada nos produtos de sexshop, circulando no imaginário coletivo e se apresenta sob diversas formas, patologizada, estimulada, disciplinada pelos sexólogos, exigida por normativas pedagógicas de manuais de autoajuda, tecnologizada pelas cirurgias estéticas e modelada pelo discurso da beleza e do ciúme. Para este artigo, em decorrência do espaço, exemplificamos com uma postagem:

Ola, [...] moro com meu marido já fazem seis anos, no começo do nosso namoro enfrentamos a maior dificuldade porque ambas as famílias não aceitavam nosso namoro, mas insistimos e fomos morar juntos. Tivemos um excelente casamento durante quatro anos e resolvemos (juntos) ter um filho. Até o primeiro ano da minha filha nosso casamento ia tudo muito bem, mas depois meu marido começou a ter um ciúme doentio, ele sempre foi ciumento, só que depois piorou e muito. Por várias vezes ele me seguiu para saber onde eu estava, passava várias vezes na rua do meu trabalho, me ligava o dia todo, e como se isso não bastasse fiscalizava até com que calcinha eu estava indo trabalhar. Isso acabou com nosso relacionamento, chegamos a falar varias vezes em separação, mas nunca nos separamos. Depois de muito conversar com ele e dizer que ele não tinha motivo nenhum para desconfiar de mim, ele aos poucos foi melhorando, mas ainda assim vivia fiscalizando onde vou, com quem vou, que roupa vou, se passo perfume, pq passei batom, e eu fui ignorando tudo isso e empurrando com a barriga. Só que agora depois de mais ou menos um ano e meio, ele começou tudo de novo, pediu minhas senhas de e-mail, começou a vistoriar meu celular, minhas roupas, e a brigar comigo por causa de coisas sem fundamento, como por exemplo, pq tenho o e-mail do meu cunhado nos meus contatos de e-mail. Eu já não estou aguentando mais, e acho que tanto eu como ele estamos juntos apenas por causa da nossa filha de dois anos e dez meses. E com todo este desgaste e insatisfação comecei a olhar com "outros olhos" um colega de trabalho que ele sempre teve um ciúme incontrolável, do tipo de até insinuar que eu já o traí com esse colega. $\mathrm{O}$ que eu faço? Estou perdida neste relacionamento. Será que é hora de realmente separar? (REGISTRO 127)

Nessa postagem, fica evidente a questão da sexualidade perturbada. $O$ marido desconfia de todas as ações da esposa no exercício da sexualidade. Reduz a esposa ao corpo e esse corpo só tem uma única dimensão, ou seja, apto para o 
exercício do sexo a toda hora, com qualquer um e em qualquer situação. O cônjuge é perturbado por esse dispositivo e com isso vive uma vida ilusória, fantasmagórica em que foca todo o relacionamento na infidelidade da esposa. São vários anos de tortura mental e física em que há uma tentativa de disciplinamento do corpo e da mente do outro, que é dado na iminência da prática "devassa" da sexualidade. Toda a intimidade do outro deve ser devastada em busca de uma possível traição. A sexualidade se faz presente como um dispositivo, pois está na roupa, no batom, no perfume, no conteúdo das conversas, nos relacionamentos com outros familiares. Foucault assevera que esse dispositivo é liberado, incentivado, estimulado na sociedade. Entretanto, deve, no caso de nossa reclamante, ficar adstrito ao cenário do lar, mas a ele escapa ou parece escapar. O marido, constituído nesse dispositivo que liberou o sexo na cultura ocidental, acha-se a ele aprisionado, enxergando-o em tudo e todos. A sexualidade é onipresente para o marido, que não percebe o quão se encontra encarcerado nesse cenário. O ciúme torna-se uma paranoia amorosa, já que o amor-paixão romântico exige a exclusividade do outro, sua dedicação a um amor simbiótico e devorador. Aí, sim, há uma violência psicológica e física simultaneamente, à medida que o cônjuge passa a ser aquele que desconfia, fiscaliza e domina o outro. O homem e a mulher são vítimas de um mesmo dispositivo que Ihes impede a vivência harmônica. É preciso esquadrinhar a vida do outro no âmbito da sexualidade e esse outro deve confessar suas culpas, quanto ao exercício da sexualidade.

O terceiro dispositivo, que também é recorrente, é o do machismo, entendido como uma formação de longa duração e que só se reforça, uma vez que continua a circular nas falas, nos jornais, nas novelas, nas letras de músicas, enfim, tendo poder de influência sobre nossas mentes e corpos. O machismo consiste em uma perspectiva assimétrica, na qual o elemento masculino é sempre dado como mais forte, mais capaz, mais eficiente, mais racional, melhor que o elemento feminino. Ele sobressai tanto em si como em comparação com o elemento feminino. Nessa perspectiva, a mulher, não raras vezes, toma sua identidade a partir do homem, mas não em posição dialógica deshierarquizada. É dada em comparação com o homem, mas valendo menos. A sua identidade passa a ser constituída a partir do masculino, mas inferiorizada. Para este artigo, exemplificamos com uma postagem: 
Olá, sou casada ha 12 anos tenho três filhas, tô gorda feia e velha, esqueci de me cuidar, não tive tempo pra vaidade, e nem sonhos profissionais, sou dona de casa, to sofrendo $\mathrm{mt}$, meu marido não me beija mais, só quer sexo, sem carinho, durante o dia nem me olha, como se eu não existisse, implica com as roupas q eu visto, diz q e pra eu usar roupa q me sirva, não sei o q fazer já fiz de td pra emagrecer e não consigo, ele não quer conversar, não me deixa trabalhar fora, o q eu faço, tô desesperada, preciso me sentir mulher, ser valorizada, mas ele acha q é frescura minha, vou fazer uma besteira se isso não mudar [...] tento escrever cartas pra ele, dizendo o q estou sentindo, mas ele nem lê, e diz pra eu parar de me fazer de coitadinha, quero me separar e ele não quer, mas não fala que me ama, diz que quer ficar perto das filhas [...] me ajudem vou ficar louca [...] quero me sentir amada como antes (REGISTRO 834).

Vemos que a reclamante reforça a assimetria entre o homem e a mulher: esta sempre em posição inferiorizada. Assevera que perdeu a identidade ao ser preterida pelo marido, quando afirma "preciso me sentir mulher", atrelando essa personalidade ao homem. Só será "mulher" novamente, quando se sentir desejada, amada, respeitada, cobiçada por esse cônjuge. Percebe-se, claramente, a ruína da reclamante, visto que é destituída de "humanidade", pois se pertence ao sexo feminino, sendo mulher, e essa feminilidade Ihe falta, então, falta ela mesma. Temos aí, o relacional e dialógico pelo avesso, pois ela só existe em relação ao marido. Aqui essa dialogia é dada em chave hierárquica uma vez que um dos polos se torna negativo frente ao outro. Já o elemento masculino, não perde sua vitalidade, força e poder, por estar apartado do elemento feminino. Os filhos, a casa, ela mesma, as possíveis amizades e história de vida que tenha experienciado se anulam frente à frieza e distância do parceiro. Típico caso discursivo-cultural do vazio feminino em um contexto que prega a sua dependência ao parceiro. Essa dependência é cultural e de difícil neutralização. Note-se que essa desvalorização de si é dada pela mulher, corroborando com o dispositivo machista, que reforça e reproduz em sua queixa. $O$ amor, inclusive, resume-se ao amor do cônjuge. Não importa o amor dos e pelos filhos, ou qualquer outra forma de amor, pois essas não Ihe conferem identidade alguma. Desse modo, a mulher também reforça a figura masculina em sua superioridade. Pela fala, chega ao absurdo de asseverar que só adquire identidade de "mulher" no relacionamento com este parceiro: "preciso me sentir mulher, ser valorizada, mas ele acha q é frescura minha". Aqui nos valemos de Foucault novamente, para quem o poder não é exercido só por um polo e não se manifesta sempre repressor, mas acontece de modo relacional, pois as bases também a ele aderem e o exercem. 
De acordo, mas o que eu quis dizer é que, para que haja um movimento de cima para baixo, é preciso que haja ao mesmo tempo uma capilaridade de baixo para cima. [...] Mas é certo que o poder dos reis da França e os aparelhos de Estado que eles pouco a pouco constituíram a partir do século $\mathrm{XI}$, tiveram como condição de possibilidade o enraizamento nos comportamentos, nos corpos, nas relações de poder locais, em que não caberia de forma alguma ver uma simples projeção do poder central (FOUCAULT, 1982, p. 250).

A mulher, aderindo ao discurso machista, reproduz valores que a subestimam, fortalecendo o poder masculino. Castañeda ${ }^{13}$ entende o machismo como um feixe de discursos e práticas que são, não raro, escamoteados nos ambientes sociais. A experiência pessoal da psicoterapeuta com seus pacientes permitiu a autora compreender que o machismo, assim como a violência, não são atributos de um dos polos da relação, ou do indivíduo, mas "uma forma de relação", pois a escuta terapêutica promoveu a possibilidade de se entender que para "todos os papéis masculinos associados ao machismo tem um correspondente feminino" (CASTAÑEDA, 2006, p. 19). Vemos o machismo, como uma moeda de duas faces, em que o logus de um existe sempre na perspectiva do outro, num código relacional, dialógico entre o masculino e o feminino.

\section{CONSIDERAÇÕES FINAIS}

Verificamos que o Brasil é um país violento desde seus primórdios, cuja cultura e ideologia do cotidiano fomentam uma perspectiva de agressão, veiculando, mormente, a partir de produtos culturais e discursos corriqueiros, uma identidade masculina instituída como viril, guerreira, forte o que, não raras vezes, justifica a violência do comportamento do homem.

Baseados em Santos e Izumino, Castañeda, Rougemont e Foucault, identificamos, nas falas, três dispositivos que, de certa maneira, influenciam comportamentos violentos: do amor-paixão, da sexualidade e do machismo.

Um dos equívocos acerca do fenômeno da violência é a forma polarizada de concebê-la, pois boa parte das pesquisas entende a violência contra a mulher, advinda apenas do indivíduo masculino, quando na realidade ela é macroscópica, pois transpassa gênero, etnia e classe social. Em graus diferentes, todos os sujeitos são ocupados pelos dispositivos descritos. A violência discursiva foi privilegiada,

13 Marina Castañeda é psicoterapeuta, no México, país que ocupa o sexto lugar no ranking das nações que mais matam mulheres no planeta. A sua de 2006 serviu-nos para entender o fenômeno do machismo como um dispositivo discursivo relacional.

R. Inter. Interdisc. INTERthesis, Florianópolis, v.14, n.2, p.132-151 Mai.-Ago. 2017 
pois as palavras carregam valores culturais que nos formam e deformam, reforçando práticas funestas. Essas falas narram como ocorrem as complexas articulações entre o microcosmo familiar e o macrocosmo cultural, demonstrando não ser possível que uma família, ao nascer mergulhada na cultura da violência, estivesse do lado de fora dela. Na perspectiva desta pesquisa, tentou-se desviar o foco dos papéis de vítimas e algozes, assumidos comumente por mulheres e homens. A pesquisa reforça a perspectiva relacional e dialógica da violência na conjugalidade, esperando vislumbrar uma possível saída a longo prazo para o cenário apresentado. 
VIOLENCE CULTURE, PASSION-LOVE, SEXUALITY AND MACHISMO: AN ANALYSIS OF FEMALE VOICES ON CONJUGAL CORRODED RELATIONSHIPS

\begin{abstract}
:
This paper analysis virtual posts from women visiting the Blog, which focuses on conjugal problems. Violence between couples is analyzed through the relational perspective based on Santos and Izumino (2005). About machismo, it is adopted Castañeda's (2006) point of view that emphasizes machismo as a behavior and a not male exclusive discourse. The passion-love ideology (Rougemont (1988) also enforces the culture of violence. The article is based on Foucault's (1982, 1984, 1995,2012 ) theoretical background in which violence and power are perceived as relational dimensions, and sexuality is also viewed as an important source of violence. The research desires to contribute on the violence against women discussion and their conjugal relations, aiming to reflect about the essentiality of changing cultural paradigms to then transform the scenery described.
\end{abstract}

Keywords: Violence Culture. Female Discourses. Sexuality. Passion-love. Machismo.

\title{
CULTURA DE LA VIOLENCIA, DISPOSITIVO DEL AMOR-PASIÓN, SEXUALIDAD Y MACHISMO: UN ANÁLISIS DEL DISCURSO FEMENINO EN RELACIONES PERTURBADAS
}

\section{Resumen:}

Este artículo analiza las publicaciones en medios digitales de visitantes femeninas de Blog, centrado en los problemas conyugales. Se analiza la violencia de las parejas por la perspectiva relacional de Santos e Izumino (2005). Sobre el machismo, se adoptó la premisa de Castañeda (2006), que lo destaca como un discurso y una práctica no exclusivos de los hombres. La ideología del amor-pasión (Rougemont 1988) también fortalece la cultura de la violencia. Partimos de las contribuciones de Foucault $(1982,1984,2012,2013)$ sobre el poder y la violencia, como relacional, y el dispositivo de la sexualidad como factor que conduce a la violencia. La investigación se propone contribuir para una reflexión sobre la violencia contra las mujeres y las relaciones conyugales, haciendo hincapié en la necesidad de cambiar los paradigmas culturales, que refuerzan actitudes y discursos violentos dentro y fuera de la familia.

Palabras Clave: Cultura de la Violencia. Discursos sobre lo Femenino. Sexualidad. Amor-Pasión. Machismo. 


\section{REFERÊNCIAS}

BAKHTIN, M.; VOLOCHÍNOV, V. N. Marxismo e filosofia da linguagem. São Paulo: Hucitec, 2014.

CASTAÑEDA, M. O machismo invisível. São Paulo: Girafa, 2006.

CONSELHO NACIONAL DE JUSTIÇA (CNJ) - Novo Diagnóstico de Pessoas Presas no Brasil, do Departamento de Monitoramento e Fiscalização do Sistema Carcerário e do Sistema de Execução de Medidas Socioeducativas - DM, Brasília, junho de 2014.

FANINI, A. M. R. A grande arte: uma abordagem estético-sociológica. 1992. $178 f$. Dissertação (Mestrado em Literatura) - Universidade Federal de Santa Catarina, 1992.

FORUM DE SEGURANÇA PÚBLICA/2016.

$<$ http://www.forumseguranca.org.br/produtos/anuario-brasileiro-de-segurancapublica/10o-anuario-brasileiro-de-seguranca-publica >. Acesso em 10 out2016.

FOUCAULT, M. Microfísica do poder. Rio de Janeiro: Graal, 1982.

FOUCAULT, M. História da sexualidade I A vontade de saber. Rio de Janeiro: Graal, 1984.

FOUCAULT, M. Vigiar e punir. Rio de Janeiro: Vozes, 2013.

FOUCAULT, M. A ordem do discurso. São Paulo: Loyola, 2012.

KRUG, E. G. et al. World report on violence and health (Relatório Mundial sobre violência e saúde). Genebra: [s.n.], 2002.

MACHADO, L. Z.; MAGALHÃES, M. T. B. Violência Conjugal: os espelhos e as marcas. Brasília: [s.n.], 1998. (Série Antropologia).

ROUGEMONT, D. O amor e o Ocidente. Rio de Janeiro: Guanabara, 1988. 
SANTOS, C. M.; IZUMINO, W. P. Violência contra as mulheres e Violência de Gênero: Notas sobre Estudos Feministas no Brasil. In.: EIAL: Estudios

Interdisciplinarios de America Latina y el Caribe, v. 16, no 1, p. 147-164, 2005.

UNITED NATIONS OFFICE ON DRUGS AND CRIME. Global study on homicide 2013. [S.I.]: UNODC, 2013.

WAISELFISZ, J. J. Mapa da violência 2015: homicídio de mulheres no Brasil. $1^{\text {a }}$ ed. Brasília: [s.n.], 2015.

\section{Artigo:}

Recebido em 20 de Novembro de 2016.

Aceito em 20 de Março de 2017. 